Black carbon reduces beneficial effect of physical activity on lung function Peer-reviewed author version

LAEREMANS, Michelle; DONS, Evi; Avila-Palencia, Ione; Carrasco-Turigas, Glòria; Orjuela-Mendoza, Juan Pablo; Anaya-Boig, Esther; Cole-Hunter, Tom; De Nazelle, Audrey; Nieuwenhuijsen, Mark; Standaert, Arnout; Van Poppel, Martine; DE BOEVER, Patrick \& INT PANIS, Luc (2018) Black carbon reduces beneficial effect of physical activity on lung function. In: MEDICINE AND SCIENCE IN SPORTS AND EXERCISE, 50(9), p. 1875-1881.

DOI: 10.1249/MSS.0000000000001632

Handle: http://hdl.handle.net/1942/27574 
See discussions, stats, and author profiles for this publication at: https://www.researchgate.net/publication/324431512

\section{Black Carbon Reduces the Beneficial Effect of Physical Activity on Lung Function}

Article in Medicine \& Science in Sports \& Exercise · April 2018

DOI: $10.1249 / \mathrm{MSS} .0000000000001632$

CITATIONS

13 authors, including:

6

Michelle Laeremans

Flemish Institute for Technological Research

38 PUBLICATIONS 74 CITATIONS

SEE PROFILE

Ione Avila-Palencia

Instituto de Salud Global de Barcelona

40 PUBLICATIONS 75 CITATIONS

SEE PROFILE

Some of the authors of this publication are also working on these related projects:

Project BlueHealth View project

Project AVENUE View project
READS

247

Evi Dons

Hasselt University

100 PUBLICATIONS 1,661 CITATIONS

SEE PROFILE

Glòria Carrasco-Turigas

Instituto de Salud Global de Barcelona

55 PUBLICATIONS 200 CITATIONS

SEE PROFILE 


\section{Medicine \& Science \\ IN \\ Sports \& Exercise}

The Official Journal of the American College of Sports Medicine www.acsm-msse.org

... Published ahead of Print

\section{Black Carbon Reduces the Beneficial Effect of Physical Activity on Lung Function}

Michelle Laeremans ${ }^{1,2}$, Evi Dons ${ }^{1,3}$, Ione Avila-Palencia ${ }^{4,5,6}$, Glòria Carrasco-Turigas ${ }^{4,5,6}$, Juan Pablo Orjuela-Mendoza ${ }^{7}$, Esther Anaya-Boig ${ }^{7}$, Tom Cole-Hunter ${ }^{4,5,6,8}$, Audrey de Nazelle ${ }^{7}$, Mark Nieuwenhuijsen ${ }^{4,5,6}$, Arnout Standaert ${ }^{1}$, Martine Van Poppel ${ }^{1}$, Patrick De Boever ${ }^{1,3}$, and Luc Int Panis ${ }^{1,2}$

${ }^{1}$ Flemish Institute for Technological Research (VITO), Mol, Belgium; ${ }^{2}$ Transportation Research Institute (IMOB), Hasselt University, Diepenbeek, Belgium; ${ }^{3}$ Centre for Environmental Sciences, Hasselt University, Diepenbeek, Belgium; ${ }^{4}$ ISGlobal, Centre for Research in Environmental Epidemiology, Barcelona, Spain; ${ }^{5}$ Universitat Pompeu Fabra, Barcelona, Spain; ${ }^{6}$ CIBER Epidemiology and Public Health, Madrid, Spain; ${ }^{7}$ Centre for Environmental Policy, Imperial College London, London, United Kingdom; ${ }^{8}$ Department of Environmental and Radiological Health Sciences, Colorado State University, Fort Collins, CO

Accepted for Publication: 26 March 2018

Medicine \& Science in Sports \& Exercise ${ }_{\circledast}$ Published ahead of Print contains articles in unedited manuscript form that have been peer reviewed and accepted for publication. This manuscript will undergo copyediting, page composition, and review of the resulting proof before it is published in its final form. Please note that during the production process errors may be discovered that could affect the content. 


\section{Black Carbon Reduces the Beneficial Effect of Physical Activity on Lung}

\section{Function}

Michelle Laeremans $^{1,2}$, Evi Dons ${ }^{1,3}$, Ione Avila-Palencia ${ }^{4,5,6}$, Glòria Carrasco-Turigas ${ }^{4,5,6}$, Juan Pablo Orjuela-Mendoza ${ }^{7}$, Esther Anaya-Boig ${ }^{7}$, Tom Cole-Hunter ${ }^{4,5,6,8}$, Audrey de Nazelle ${ }^{7}$, Mark Nieuwenhuijsen ${ }^{4,5,6}$, Arnout Standaert ${ }^{1}$, Martine Van Poppel ${ }^{1}$, Patrick De Boever ${ }^{1,3}$, and Luc Int Panis ${ }^{1,2}$

${ }^{1}$ Flemish Institute for Technological Research (VITO), Mol, Belgium; ${ }^{2}$ Transportation Research Institute (IMOB), Hasselt University, Diepenbeek, Belgium; ${ }^{3}$ Centre for Environmental Sciences, Hasselt University, Diepenbeek, Belgium; ${ }^{4}$ ISGlobal, Centre for Research in Environmental Epidemiology, Barcelona, Spain; ${ }^{5}$ Universitat Pompeu Fabra, Barcelona, Spain; ${ }^{6}$ CIBER Epidemiology and Public Health, Madrid, Spain; ${ }^{7}$ Centre for Environmental Policy,

Imperial College London, London, United Kingdom; ${ }^{8}$ Department of Environmental and Radiological Health Sciences, Colorado State University, Fort Collins, CO

Correspondence to: Prof dr Luc Int Panis, Flemish Institute for Technological Research (VITO), Boeretang 200, 2400 Mol, Belgium, e-mail: luc.intpanis@vito.be

This research received funding from the European Union's Seventh Framework Program to the PASTA project under grant agreement No. 602624 (FP7-HEALTH-2013-INNOVATION-1) (Physical Activity through Sustainable Transport Approaches). Duration 1 November 2013 to 31 
October 2017. Michelle Laeremans is supported by a VITO PhD scholarship. Avi Dons is supported by a postdoctoral scholarship from FWO-Research Foundation Flanders. Juan Pablo Orjuela-Mendoza received a beneficiary grant from Colciencias (Administrative Department of Science, Technology and Innovation of the Colombian Government) (grant number 646). All authors declare that they have no conflicts of interest and that the results of the study are presented clearly, honestly, and without fabrication, falsification, or inappropriate data manipulation. The results of the present study do not constitute endorsement by ACSM.

Copyright (C 2018 by the American College of Sports Medicine. Unauthorized reproduction of this article is prohibited. 


\section{Abstract}

Introduction: When physical activity is promoted in urban outdoor settings (e.g. walking and cycling), individuals are also exposed to air pollution. It has been reported that short-term lung function increases as a response to physical activity, but this beneficial effect is hampered when elevated air pollution concentrations are observed. Our study assessed the long-term impact of air pollution on the pulmonary health benefit of physical activity. Methods: Wearable sensors were used to monitor physical activity levels (SenseWear) and exposure to black carbon (microAeth) of 115 healthy adults during one week in three European cities (Antwerp, Barcelona, London). The experiment was repeated in three different seasons to approximate long-term behavior. Spirometry tests were performed at the beginning and end of each measurement week. All results were averaged on a participant level as a proxy for long-term lung function. Mixed effect regression models were used to analyze the long-term impact of physical activity, black carbon and their interaction on lung function parameters $\mathrm{FEV}_{1}, \mathrm{FVC}_{\text {, }}$ $\mathrm{FEV}_{1} / \mathrm{FVC}, \mathrm{FEF}_{25-75}$ and $\mathrm{PEF}$. Interaction plots were used to interpret the significant interaction effects. Results: Negative interaction effects of physical activity and black carbon exposure on $\mathrm{FEV}_{1}(\mathrm{p}=0.07), \mathrm{FEV}_{1} / \mathrm{FVC}(\mathrm{p}=0.03)$ and $\mathrm{FEF}_{25-75}(\mathrm{p}=0.03)$ were observed. For black carbon concentrations up to approximately $1 \mu \mathrm{g} / \mathrm{m}^{3}$, an additional METhour per week resulted in a trend towards lung function increases $\left(\mathrm{FEV}_{1}, \mathrm{FEV}_{1} / \mathrm{FVC}\right.$ and $\mathrm{FEF}_{25-75}$ increased $5.6 \mathrm{~mL}, 0.1 \%$ and 14.5 $\mathrm{mL} / \mathrm{s}$, respectively). Conclusion: We found that lung function improved with physical activity at low black carbon levels. This beneficial effect decreased in higher air pollution concentrations. Our results suggest a greater need to reduce air pollution exposures during physical activity.

Key words: air pollution, active mobility, Tiffeneau, FVC, $\mathrm{FEV}_{1}$ 


\section{Introduction / Background}

Today's global physical inactivity pandemic is responsible for approximately five million premature deaths annually (1). However, when physical activity in urban outdoor settings (e.g. walking and cycling) is promoted, air quality may need to be taken into account.

Long-term air pollution exposure contributes to increased prevalence of cardiovascular and respiratory diseases (2). Globally, many people live in urbanized regions, which are hotspots of air pollution due to poor urban and transport planning (3). Consequently, walking, cycling and other forms of both incidental and intentional physical activity in urban environments often involve exposure to high concentrations of air pollution.

Higher ventilation rates during physical activity result in an increased pollutant dose and deeper penetration of particles into the lungs $(4,5)$. Nevertheless, various health impact assessments have been carried out and reported that the overall benefits of physical activity outweigh the risks of air pollution (6-8). Also, the Danish Diet, Cancer and Health Cohort did not observe a modification effect of air pollution on the relationship between physical activity and all-cause mortality (9). However, short-term respiratory responses to physical activity have been shown to alter with increasing air pollution concentrations $(10,11)$. A recent study in older adults, with and without pre-existing chronic obstructive pulmonary disease (COPD) or ischaemic heart disease, found that the beneficial effects of walking on lung function were lost after a two-hour walk in a polluted environment (11). In addition, lung function responses to physical activity in healthy participants also differed when air pollution was taken into account $(10,12)$. Evidence on the chronic impact of air pollution on the health benefit of physical activity for specific physiological systems remains absent (5). Therefore, the main aims of the current study were: (1) to assess the chronic effects of physical activity and air pollution on lung function and (2) to assess whether 
the pulmonary responses to physical activity and air pollution interact in a sample of healthy adults across three European cities.

\section{Methods}

\section{Study design and participants}

The framework of this study was the PASTA project (Physical Activity through Sustainable Transport Approaches). In this project, data on physical activity and travel behavior among over 12,500 volunteers living or working in seven European cities (Antwerp, Barcelona, London, Örebro, Rome, Vienna, Zurich) was collected through an online survey $(13,14)$. From this sample, 122 participants were selected to participate in a real-life monitoring study in three cities (Antwerp: 41 participants, Barcelona: 41 participants, London: 40 participants). High-resolution data on physical activity and black carbon (BC) exposure was collected during seven consecutive days using wearable sensors. Lung function was assessed with a spirometry test at the beginning and end of the measurement week. Each participant repeated the measurement week three times: in the mid-season (spring or autumn), in the summer and in the winter, between February 2015 and March 2016. Eligible participants were non-smoking, 18-65 year olds with a BMI below 30 and no self-reported cardiovascular, respiratory or neurological condition. The study was approved by the Ethics Committee of the University hospital in Antwerp (UZA), the Clinical Research Ethical Committee of the Parc de Salut Mar in Barcelona and the Imperial College Research Ethics Committee in London. All participants gave written informed consent prior to participation. 


\section{Physical activity assessment}

Physical activity was objectively measured with the SenseWear armband (model MF-SW, BodyMedia, USA). This multi-sensor body monitor measures heat flux, galvanic skin response, skin temperature and 3-axis accelerometry. The sensor was worn on the triceps muscle of the left arm and was only removed when there was contact with water (bathing, showering, etc.); wearing time was on average $96 \pm 4 \%$ of the total time. Age, sex, body weight and height of the participants were entered in the SenseWear professional software (version 8.0). Energy expenditure and METs were calculated on a one-minute basis using proprietary algorithms based on pattern recognition (15). For each measurement week, the amount of METhours was calculated in $\mathrm{R}$ version 3.3.1. Only bouts of at least 10 consecutive minutes with an intensity $\geq 3$ METs were considered. This is in accordance with the WHO recommendations on physical activity for health (16). To clarify, an activity that requires 3 METs is walking the dog and doing this for one hour results in 3 METhours (according to the compendium of physical activities (17)).

\section{BC exposure assessment}

Personal exposure to $\mathrm{BC}$ was assessed with the microAeth (model AE51, Aethlabs, USA). Ambient air was drawn over a Teflon-coated borosilicate glass fibre filter at a flow rate of $100 \mathrm{~mL} / \mathrm{min}$, resulting in $\mathrm{BC}$ accumulation on the filter. Light attenuation at a wavelength of 880 $\mathrm{nm}$ was measured and converted into a $\mathrm{BC}$ concentration $\left(\mathrm{ng} / \mathrm{m}^{3}\right)$. The device was set to estimate the average $\mathrm{BC}$ concentration every five minutes. Participants always carried the device with them and replaced the filter every two days to prevent saturation. For indoor activities, participants left the microAeth in the room where they spent most of their time. A short tube was attached to the inlet of the microAeth which enabled participants to carry the device in a bag. 
Raw BC data were smoothened with the ONA algorithm (Optimized Noise-Reduction Algorithm; developed by the Environmental Protection Agency), and data tagged with an error code that could potentially impact concentration levels were excluded.

\section{Lung function measurement}

Spirometry (EasyOne, ndd Medical Technologies) was performed according to the European Respiratory Society and the American Thoracic Society guidelines (18,19). Lung function parameters selected for this study are forced expiratory volume in the first second $\left(\mathrm{FEV}_{1}\right)$, forced vital capacity (FVC), the Tiffeneau index $\left(\mathrm{FEV}_{1} / \mathrm{FVC}\right)$, peak expiratory flow (PEF) and forced expiratory flow at $25 \%$ to $75 \%$ of the $\mathrm{FVC}\left(\mathrm{FEF}_{25-75}\right)$. Percentage predicted values of $\mathrm{FEV}_{1}$ and FVC were calculated based on the Global Lung Function 2012 equations.

\section{Analysis}

For each measurement week, the participants' physical activity level was calculated as total METhours, and their $\mathrm{BC}$ exposure was averaged. We calculated the mean of the three measurements per participant as a proxy for long-term physical activity behavior and long-term personal BC exposure. This is justified as we objectively measured physical activity and BC concentrations during a whole week in three different seasons. Consequently, differences due to seasonal changes were accounted for. Three participants did not complete all three measurement weeks and were excluded from the analysis. Also, only non-smokers $(n=100)$ and former smokers $(n=19)$ were recruited. Pack years of former smokers were low with an average of 2.7 \pm 2.9 . This corresponds to 20 cigarettes per day during 2.7 years. Four of those former smokers were excluded from the analysis since they quit smoking less than 5 years ago. This resulted in a total of 115 eligible participants out of 122. Long-term lung function parameters 
were approximated by calculating the average $\mathrm{FEV}_{1}, \mathrm{FVC}, \mathrm{FEV}_{1} / \mathrm{FVC}, \mathrm{FEF}_{25-75}$ and $\mathrm{PEF}$ per participant.

The study population was described by sex, age, ethnicity, height, BMI, and education level. For categorical variables the amount (n) and percentage was reported. Arithmetic mean and standard deviation (SD) were used for continuous variables and pulmonary outcomes. In addition, the overall and city-specific median and interquartile range (IQR) of physical activity and BC concentrations were calculated.

The effects of long-term physical activity, air pollution and their interaction were tested using mixed effect regression models where city was introduced as a random variable. First, we tested the effects of physical activity and BC on lung function separately. Then the effects of physical activity and $\mathrm{BC}$ were estimated together in one single model. Finally, models including the interaction term were tested. All models included sex, age and height based on the European Respiratory Society and the American Thoracic Society guidelines (18). To account for socioeconomic differences, education level was also added as a covariate.

The significance level was set at $\mathrm{p}<0.05$. When trends towards significant interaction effects were observed $(\mathrm{p}<0.1)$, regression estimates of physical activity were plotted with their $95 \%$ confidence interval as a function of $\mathrm{BC}$ concentrations in an interaction plot.

R software version 3.3.1 was used for data processing and analysis. Random intercept models were tested with the lme4 and lmerTest R-packages for mixed effect regression analysis. All marginal residuals were normally distributed. Interaction plots were made using the R-package Interplot. 


\section{Results}

A total of 115 healthy adults were included in the analysis. Almost half of the study population (44\%) were males; 94\% were Caucasian and 90\% had a higher education degree (Table 1). They were on average $36.6 \pm 10$ years old, $1.7 \pm 0.1 \mathrm{~m}$ tall with a BMI of $23.7 \pm 3 \mathrm{~kg} / \mathrm{m}^{2}$. Long-term $\mathrm{FEV}_{1}$ ranged from 2.28 to $5.13 \mathrm{~L}$ with an average of $3.53 \pm 0.70 \mathrm{~L}$ (mean $\%$ predicted $\mathrm{FEV}_{1}$ : $93.9 \pm 10.6 \%$ ); FVC ranged from 2.63 to $6.78 \mathrm{~L}$ with an average of $4.44 \pm 0.92 \mathrm{~L}$ (mean $\%$ predicted FVC: $96.8 \pm 10.7 \%$ ). The median, long-term $\mathrm{FEV}_{1} / \mathrm{FVC}$ ratio was $80.7 \%$. Hence, we recruited a sample of participants with normal lung function (18).

Table 2 shows the participants' physical activity level and $\mathrm{BC}$ exposure aggregated over all three measurement weeks per individual. In general, we recruited a physically active sample: the median amount of METhours per week was 42, which exceeds the WHO recommendation of 10 METhours. The least active population was recruited in Barcelona, while a similar physical activity level was observed for participants in Antwerp and London. On the other hand, BC concentrations were highest in Barcelona. Overall, median BC exposures were $1.4 \mu \mathrm{g} / \mathrm{m}^{3}$.

Mixed effect regression analysis was performed using models with and without the interaction term of physical activity and $\mathrm{BC}$ exposure (Table 3). There were no significant effects of physical activity and $\mathrm{BC}$ on the lung function parameters in models excluding the interaction term. This changed when the interaction term was included. These models showed significant, negative interaction effects of physical activity and $\mathrm{BC}$ exposure on $\mathrm{FEV}_{1}(\mathrm{p}=0.07)$, the $\mathrm{FEV}_{1} / \mathrm{FVC}$ ratio $(\mathrm{p}=0.03)$ and $\mathrm{FEF}_{25-75}(\mathrm{p}=0.03)$.

The effect of physical activity increased to borderline significant levels when the interaction term was included. According to these models, $\mathrm{FEV}_{1}, \mathrm{FEV}_{1} / \mathrm{FVC}$ and $\mathrm{FEF}_{25-75}$ would gain $5.6 \mathrm{~mL}$ $(\mathrm{p}=0.13), 0.1 \%(\mathrm{p}=0.08)$ and $14.5 \mathrm{~mL} / \mathrm{s}(\mathrm{p}=0.06)$ per additional weekly METhour. However, the 
interaction term also shows trends towards significance which means that the value and significance of the main physical activity effect should be interpreted for specific BC concentrations.

None of the models could detect a significant effect of physical activity and BC on FVC and PEF.

The effects of physical activity on $\mathrm{FEV}_{1}, \mathrm{FEV}_{1} / \mathrm{FVC}$ and $\mathrm{FEF}_{25-75}$ were plotted as a function of BC concentration. Figure 1 visualizes how increasing BC concentrations modify the effect of physical activity on $\mathrm{FEV}_{1}, \mathrm{FEV}_{1} / \mathrm{FVC}$ and $\mathrm{FEF}_{25-75}$. The dashed vertical line represents the $\mathrm{BC}$ concentrations where the $95 \%$ confidence interval of the estimated effect of physical activity on $\mathrm{FEV}_{1}, \mathrm{FEV}_{1} / \mathrm{FVC}$ and $\mathrm{FEF}_{25-75}$ only included negative values. Consequently, based on our results, $\mathrm{FEV}_{1}, \mathrm{FEV}_{1} / \mathrm{FVC}$ and $\mathrm{FEF}_{25-75}$ improves with physical activity at lower $\mathrm{BC}$ concentrations. At high $\mathrm{BC}$ levels, additional physical activity may reduce these lung function parameters.

\section{Discussion}

This is the first study to examine the combined long-term effects of air pollution and physical activity on lung function using personal measurements obtained with wearable devices. We found that physical activity is associated with an improved pulmonary function at low BC concentrations. This respiratory benefit decreased when BC concentrations increased.

$\mathrm{BC}$ is a fraction of particulate matter with most particles having an aerodynamic diameter smaller than $1 \mu \mathrm{m}$. Such small particles are believed to be more harmful than particles of larger sizes (20). This makes BC a valuable marker to study physiological effects of air pollution (21). Overall, we measured a median $\mathrm{BC}$ concentration of $1.4 \mu \mathrm{g} / \mathrm{m}^{3}$, with the highest concentrations 
in Barcelona $\left(1.7 \mu \mathrm{g} / \mathrm{m}^{3}\right)$. These concentrations were similar to those measured in the ESCAPE project, which covered a broad range of areas in Europe $\left(\mathrm{PM}_{2.5}\right.$ absorbance was converted to $\mathrm{BC}$ based on the formulas in Dons (24) and Gan et al. (25)). The ESCAPE cohort found a negative association between long-term $\mathrm{NO}_{2}$ and $\mathrm{PM}_{10}$ exposure and lung function in adults (24). However, the relationship was not significant for $\mathrm{PM}_{2.5}$ absorbance (a marker for $\mathrm{BC}$ ) which is consistent with our results.

At low BC concentrations up to approximately $1 \mu \mathrm{g} / \mathrm{m}^{3}$, the effect of an additional METhour per week on $\mathrm{FEV}_{1}, \mathrm{FEV}_{1} / \mathrm{FVC}$ and $\mathrm{FEF} 25-75$ was an increase of $5.6 \mathrm{~mL}, 0.1 \%$ and $14.5 \mathrm{~mL} / \mathrm{s}$ respectively. This benefit decreased with increasing $\mathrm{BC}$ concentrations. Our findings are in line with observations from a study by Cheng et al. (2003), executed in Texas. In this study, selfreported exercise patterns of healthy adults between 25 and 55 years old were associated with spirometry results (25). These participants were categorized according to their physical activity level where the highly active participants were approximately 16 METhour per week more active than those with a low physical activity level (based on the formulas in Ainsworth et al. (28)). Highly active men had a $130 \mathrm{~mL}$ higher $\mathrm{FEV}_{1}$; for women, the difference was $80 \mathrm{~mL}$. This corresponded to a $8 \mathrm{~mL}$ and $5 \mathrm{~mL} \mathrm{FEV}_{1}$ increase per METhour for men and women respectively with an annual BC concentration $0.7 \mu \mathrm{g} / \mathrm{m}^{3}$ in Texas, similar to our results (26). Other studies have also observed correlations between physical activity related variables and $\mathrm{FEV}_{1}$ or $\mathrm{FVC}$ $(27,28)$.

Little research has been done on the chronic impact of air pollution on the respiratory benefits of physical activity. A review by Giles et al. (2014) suggested that chronic exposure during exercise has important consequences for respiratory function (29). Hence, a higher prevalence of exercise-induced bronchoconstriction, asthma and lower lung function has been observed in 
athletes who train in environments with high particulate matter emissions (5). Moreover, reductions in respiratory mortality associated with cycling were greater for participants with low to moderate compared to high air pollution exposure in the Danish Diet, Cancer and Health Cohort (9).

It is well documented that inhalation of air pollutants causes oxidative damage and inflammation in the respiratory system resulting in airway obstruction and a reduced $\mathrm{FEV}_{1}(5,30,31)$. Exercising in polluted air also results in inhalation of a higher pollutant dose which may enhance its adverse respiratory effects $(4,5,31)$. Contrary, regular physical activity improves endurance and strength of the respiratory muscles resulting in an increased $\mathrm{FEV}_{1}$ (30). However, compared to the cardiovascular system, respiratory adaptations to physical activity are rather small because the lungs are already equipped to deal with the demands of high intensity exercise. Consequently, exercise in elevated air pollution concentrations may lead to a level of obstruction potentially outweighing the beneficial effect of physical activity on $\mathrm{FEV}_{1}$ and $\mathrm{FEF}_{25-75}$. Therefore, chronic exposure to high air pollution doses during physical activity may result in a decreased $\mathrm{FEV}_{1}, \mathrm{FEV}_{1} / \mathrm{FVC}$ and $\mathrm{FEF}_{25-75}$. Since $\mathrm{FEF}_{25-75}$ specifically informs us about small airway function, this may indicate that physical activity and $\mathrm{BC}$ interact at this level $(32,33)$.

Contrary, various health impact assessment reported that the overall physical activity benefits outweigh the negative physiological effects of air pollution (8). However, the modification effects on physiological systems are potentially masked in previous studies as they did not investigate such subclinical reactions. Our results suggest that there may be a greater need to reduce air pollution exposures during physical activity than was previously thought.

Our sample consisted of healthy, highly educated adults with an average $\mathrm{FEV}_{1} / \mathrm{FVC}$ ratio of $80.1 \pm 6.4 \%$. The level of physical activity measured in our sample meets the WHO 
recommendation of 600 METminutes to maintain health. Overall, the IQR of measured METhours falls within light to moderate physical activity levels (2). Our findings aren't entirely representative of the general population as we recruited mostly active and highly educated volunteers of Caucasian ethnicity. We covered, however, multiple European cities which is unique in this field of research. We also recruited a larger sample compared to previous studies where air pollution exposure was assessed on a personal level (12,34). Moreover, measuring air pollution exposure and physical activity with wearable sensors reduces the risk of exposure misclassification. This is of particular importance when studying traffic-related pollutants such as $\mathrm{BC}$ of which the concentrations rapidly change in space and time (5). Accurately assessing both physical activity and air pollution exposure remains a major challenge in epidemiological research. In addition, we were able to use our personal measurements as a proxy for long-term behavior as all participants collected exposure data in three different seasons.

It has been reported that the SenseWear underestimates energy expenditure during high intensity activities which is a limitation of our study design (35). However, especially MET values above 10 METs are underestimated which our participants only achieved during $0.2 \%$ of their time awake (35). In addition, the most recent version of the SenseWear provides the best estimation compared to previous SenseWear versions and the Actigraph, the most widely used wearable physical activity tracker in research. Another limitation is that only a limited number of participants was exposed to the highest $\mathrm{BC}$ concentrations where we found a negative relationship between physical activity and respiratory health. Consequently, we were unable to robustly characterize the association at these $\mathrm{BC}$ concentrations. Also, the addition of an interaction term to our models resulted in wider confidence intervals. This may be due to the limited amount of data available for each combination of physical activity and BC levels. While 
our results are of potential interest to public health, the study needs to be replicated in a larger study sample to confirm them. Finally, high average physical activity levels of our participants may have affected the results. Potentially, the respiratory benefit of physical activity in low BC concentrations is larger in a less active sample. In addition, the interaction effect may be smaller since the baseline amount of inhaled particles during physical activity would be lower, also lowering the chances to provide a respiratory hazard.

Due to the potentially high impact on public health, we recommend future research to further characterize the modification effect of air pollution on the relationship between physical activity and long-term respiratory health. We suggest to (1) complement spirometry with other measures providing information on different parts of the respiratory system (e.g. frequency of self-reported respiratory symptoms of both the upper and lower tract), and (2) to investigate the combined effects of air pollution and physical activity in vulnerable sub-populations such as children, athletes and pulmonary patients.

\section{Conclusion}

This is the first study executed in multiple European cities simultaneously that integrated effects of air pollution and physical activity to assess their combined impact on pulmonary function. We found a long-term beneficial effect of long-term physical activity on respiratory at low BC concentrations. The beneficial effect decreased with increasing yearly, average BC concentrations in a healthy adult population. This illustrates the need for an integrated approach to better understand the health impact of strategies and policy measures that try to tackle physical inactivity and pollution. 


\section{Acknowledgements}

We are grateful to all study participants, and to Eva Govarts for her excellent support in the statistical analysis.

\section{Conflicts of Interest and Source of Funding:}

This research received funding from the European Union's Seventh Framework Program to the PASTA project under grant agreement No. 602624 (FP7-HEALTH-2013-INNOVATION-1) (Physical Activity through Sustainable Transport Approaches). Duration 1 November 2013 to 31 October 2017. Michelle Laeremans is supported by a VITO PhD scholarship. Evi Dons is supported by a postdoctoral scholarship from FWO-Research Foundation Flanders. Juan Pablo Orjuela-Mendoza received a beneficiary grant from Colciencias (Administrative Department of Science, Technology and Innovation of the Colombian Government) (grant number 646). All authors declare that they have no conflicts of interest and that the results of the study are presented clearly, honestly, and without fabrication, falsification, or inappropriate data manipulation. The results of the present study do not constitute endorsement by ACSM.

\section{Ethics committee approval}

The study was approved by the Ethics Committee of the University hospital in Antwerp (UZA), the Clinical Research Ethical Committee of the Parc de Salut Mar in Barcelona and the Imperial College Research Ethics Committee in London. 


\section{References}

1. Lee I, Shiroma EJ, Lobelo F, Puska P, Blair SN, Katzmarzyk PT. Effect of physical inactivity on major non-communicable diseases worldwide: an analysis of burden of disease and life expectancy. Lancet. 2012;380(9838):219-29.

2. Lim SS, Vos T, Flaxman AD, et al. A comparative risk assessment of burden of disease and injury attributable to 67 risk factors and risk factor clusters in 21 regions , 1990 2010: a systematic analysis for the Global Burden of Disease Study 2010. Lancet. 2012;380:2224-2060.

3. Nieuwenhuijsen MJ. Urban and transport planning, environmental exposures and healthnew concepts, methods and tools to improve health in cities. Environ Heal. 2016;15(Suppl 1):38;161-71.

4. Dons E, Laeremans M, Orjuela JP, et al. Wearable sensors for personal monitoring and estimation of inhaled traffic-related air pollution: evaluation of methods. Environ Sci Technol. 2017;51(3):1859-67.

5. Rundell KW. Effect of air pollution on athlete health and performance. Br J Sports Med. 2012;46(6):407-12.

6. Johan de Hartog J, Boogaard H, Nijland H, Hoek G. Do the health benefits of cycling outweigh the risks? Environ Health Perspect. 2010 Aug;118(8):1109-16.

7. Buekers J, Dons E, Elen B, Int Panis L. Health impact model for modal shift from car use to cycling or walking in Flanders: application to two bicycle highways. J Transp Heal. 2015;2(4):549-62.

8. Mueller N, Rojas-rueda D, Cole-hunter T, et al. Health impact assessment of active 
transportation: A systematic review. Prev Med (Baltim). 2015;76:103-14.

9. Andersen ZJ, de Nazelle A, Mendez MA, et al. A study of the combined effects of physical activity and air pollution on mortality in elderly urban residents: The Danish Diet, Cancer, and Health Cohort. Environ Heal Perspect Heal Perspect. 2015;123(6):55763.

10. Matt F, Cole-hunter T, Donaire-Gonzalez D, et al. Acute respiratory response to trafficrelated air pollution during physical activity performance. Environ Int. 2016;97:45-55.

11. Sinharay R, Gong J, Barratt B, et al. Respiratory and cardiovascular responses to walking down a traffic-polluted road compared with walking in a traffic-free area in participants aged 60 years and older with chronic lung or heart disease and age-matched healthy controls: a randomised, crosso. Lancet. 2017;6736(17):1-11.

12. Kubesch N, de Nazelle A, Westerdahl D, et al. Respiratory and inflammatory responses to short-term exposure to traffic-related air pollution with and without moderate physical activity. Occup Environ Med. 2015;72(4):284-93.

13. Dons E, Götschi T, Nieuwenhuijsen M, et al. Physical Activity through Sustainable Transport Approaches (PASTA): protocol for a multi-centre, longitudinal study. BMC Public Health. 2015;15(1126):1-11.

14. Gerike R, de Nazelle A, Nieuwenhuijsen M, et al. Physical Activity through Sustainable Transport Approaches (PASTA): a study protocol for a multicentre project. BMJ Open. 2016;6(1):1-11.

15. Bassett DRJ, Rowlands A V, Trost SG. Calibration and validation of wearables monitors. Med Sci Sports Exerc. 2012;44(1):1-13.

16. WHO. Global recommendations on physical activity for health. 2010. 58 p. 
17. Ainsworth BE, Haskell WIL, Whitt MC, et al. Compendium of physical activities: an update of activity codes and MET intensities. Med Sci Sports Exerc. 2000;32(9 Suppl):S498-504.

18. Quanjer PH, Stanojevic S, Cole TJ, et al. Multi-ethnic reference values for spirometry for the 3-95 year age range: the global lung function 2012 equations. Eur Respir J. 2012;40(6):1324-43.

19. Miller MR, Hankinson J, Brusasco V, et al. Standardisation of spirometry. Eur Respir J. $2005 ; 26(2): 1-22$.

20. Seaton A, Godden D, MacNee W, Donaldson K. Particulate air pollution and acute health effects. Lancet. 1995;345(8943):176-8.

21. Janssen NAH, Hoek G, Simic-Lawson M, et al. Black carbon as an additional indicator of the adverse health effects of airborne particles compared with PM10 and PM2.5. Environ Health Perspect. 2011;119(12):1691-9.

22. Dons E. Air pollution exposure assessment through personal monitoring and activitybased modeling [dissertation]. Hasselt University; 2013. 302 p.

23. Gan WQ, Koehoorn M, Davies HW, Demers PA, Tamburic L, Brauer M. Long-term exposure to traffic-related air pollution and the risk of coronary heart disease hospitalization and mortality. Environ Health Perspect. 2011;119(4):501-7.

24. Adam M, Schikowski T, Carsin AE, et al. Adult lung function and long-term air pollution exposure. ESCAPE: a multicentre cohort study and meta-analysis. Eur Respir J. 2015;45(1):38-50.

25. Cheng YJ, Macera CA, Addy CL, Sy FS, Wieland D, Blair SN. Effects of physical activity on exercise tests and respiratory function. Br J Sports Med. 2003;37(6):521-8. 
26. Barrett TE, Sheesley RJ. Urban impacts on regional carbonaceous aerosols: case study in central Texas. J Air Waste Manage Assoc. 2014;64(8):917-26.

27. Camarri B, Eastwood PR, Cecins NM, Thompson PJ, Jenkins S. Six minute walk distance in healthy subjects aged 55 - 75 years. Respir Med. 2006;100(4):658-65.

28. Jakes RW, Day NE, Patel B, et al. Physical inactivity is associated with lower forced expiratory volume in 1 second - European Prospective Investigation into Cancer-Norfolk prospective population study. Am J Epidemiol. 2002;156(2):139-47.

29. Giles L V, Koehle MS. The health effects of exercising in air pollution. Sport Med. 2014;44(2):223-49.

30. Mckenzie DC. Respiratory physiology: adaptations to high-level exercise. Br J Sports Med. 2012;46(6):381-4.

31. Int Panis L, de Geus B, Vandenbulcke G, et al. Exposure to particulate matter in traffic: a comparison of cyclists and car passengers. Atmos Environ. 2010;44(19):2263-70.

32. Rao DR, Gaffin JM, Baxi SN, Sheenan WJ, Hoffman EB, Phipatanakul W. The utility of forced expiratory flow between $25 \%$ and $75 \%$ of vital capacity in predicting childhood asthma morbidity and severity. J asthma. 2012;49(6):586-92.

33. Marseglia GL, Cirillo I, Vizzaccaro A, et al. Role of forced expiratory flow at 25-75\% as an early marker of small airways impairment in subjects with allergic rhinitis. J Allergy Clin Immunol. 2007;28(1):74-9.

34. Weichenthal S, Kulka R, Dubeau A, Martin C, Wang D, Dales R. Traffic-related air pollution and acute changes in heart rate variability and respiratory function in urban cyclists. Environ Health Perspect. 2011;119(10):1373-8.

35. Lopez GA, Brønd JC, Dencker M, Arvidsson D. Validation of SenseWear Armband in children, adolescents, and adults. Scand J Med Sci Sports. 2017;28(2):487-495. 
Figure captions

Figure 1 Regression estimates of physical activity effects (95\% confidence interval) on $\mathrm{FEV}_{1}$ (A), GEV 1 /FVC (B) and $\mathrm{FEF}_{25-75}$ (C) as a function of BC. Barplots on the $\mathrm{x}$-axis represent the number of participants exposed to the corresponding $\mathrm{BC}$ concentration. The dashed vertical line represents the $\mathrm{BC}$ concentration where the $95 \%$ confidence interval of the effect of physical activity only includes negative values. This means that the lung function parameters decrease with additional physical activity at $\mathrm{BC}$ concentrations above the highlighted levels.

Copyright (@) 2018 by the American College of Sports Medicine. Unauthorized reproduction of this article is prohibited. 
Figure 1
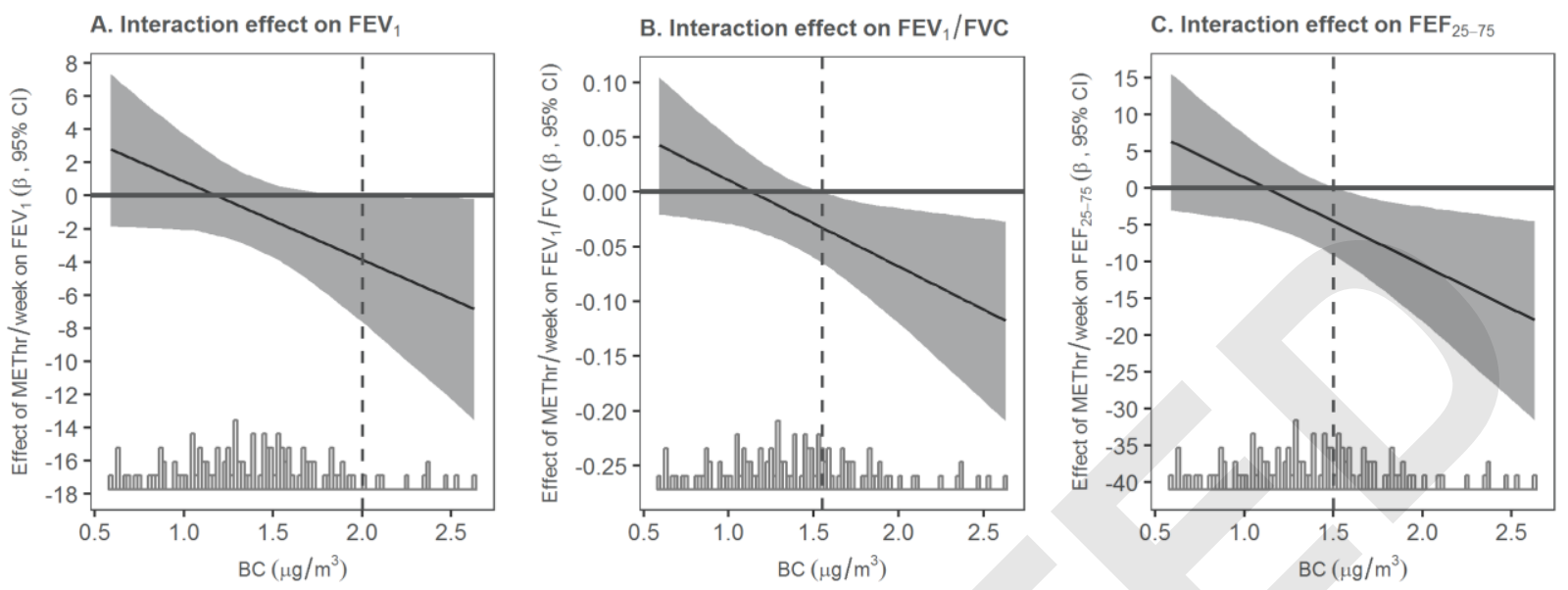

Copyright ( $\odot 2018$ by the American College of Sports Medicine. Unauthorized reproduction of this article is prohibited. 
Table 1 Characteristics of the study population and pulmonary outcomes aggregated over all sessions per individual $(\mathbf{n}=115)$. Categorical characteristics are reported as $n(\%)$; continuous variables are reported as mean $\pm S D$. The percentqge predicted values of FEVI and FVC were calculated based on the 2012 Global Lung Function equations.

\begin{tabular}{|c|c|}
\hline \multicolumn{2}{|l|}{ Personal characteristics } \\
\hline Men & $51(44 \%)$ \\
\hline Age (years) & $36.6 \pm 10$ \\
\hline Ethnicity (Caucasian) & $108(94 \%)$ \\
\hline Height (m) & $1.7 \pm 0.1$ \\
\hline BMI $\left(\mathrm{kg} / \mathrm{m}^{2}\right)$ & $23.7 \pm 3$ \\
\hline Higher education & $104(90 \%)$ \\
\hline \multicolumn{2}{|c|}{ Pulmonary outcomes (mean \pm SD) } \\
\hline $\mathrm{FEV}_{1}$ & $\begin{array}{l}3.53 \pm 0.69 \mathrm{~L} \\
93.9 \pm 10.6 \% \text { pred. }\end{array}$ \\
\hline FVC & $\begin{array}{l}4.44 \pm 0.92 \mathrm{~L} \\
96.8 \pm 10.7 \% \text { pred. }\end{array}$ \\
\hline $\mathrm{FEV}_{1} / \mathrm{FVC}$ & $80 \pm 6.3 \%$ \\
\hline PEF & $8.58 \pm 1.87 \mathrm{~L} / \mathrm{s}$ \\
\hline $\mathrm{FEF}_{25-75}$ & $3.41 \pm 0.95 \mathrm{~L} / \mathrm{s}$ \\
\hline
\end{tabular}


Table 2 Median and IQR of the average physical activity level (PA) and BC concentrations per participant $(n=115)$.

\begin{tabular}{l|llll|}
\hline & Overall & Antwerp & Barcelona & \multicolumn{1}{c}{ London } \\
\hline PA level (METhours/week) & $42(28-74)$ & $56(36-89)$ & $32(17-59)$ & $51(29-82)$ \\
BC $\left(\mu \mathrm{g} / \mathrm{m}^{3}\right)$ & $1.4(1.1-1.7)$ & $1.3(1.1-1.6)$ & $1.7(1.5-1.9)$ & $1.3(1.0-1.5)$ \\
\cline { 2 - 5 }
\end{tabular}


Table 3 Estimated effects of physical activity (METhour/week), BC $\left(\mu \mathrm{g} / \mathrm{m}^{3}\right)$ and their interaction on

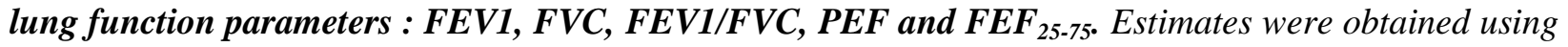
mixed effect regression analysis $(n=115)$. The first column specifies the main effects that were included in the associated models. All models included sex, age, height and education levels as covariates. City was introduced as a random effect. $P A=$ physical activity; $B C=$ Black carbon

\begin{tabular}{|c|c|c|c|c|c|c|}
\hline \multirow{2}{*}{$\begin{array}{c}\text { Outcome } \\
\text { FEV1 (mL) }\end{array}$} & \multicolumn{2}{|c|}{$\begin{array}{c}\text { PA } \\
\text { (METhour/week) }\end{array}$} & \multicolumn{2}{|l|}{$\begin{array}{c}\mathrm{BC} \\
\left(\mu \mathrm{g} / \mathrm{m}^{3}\right)\end{array}$} & \multicolumn{2}{|l|}{$\mathrm{PA} \times \mathrm{BC}$} \\
\hline & $\beta(95 \% \mathrm{CI})$ & $\mathrm{p}$ & $\beta(95 \% \mathrm{CI})$ & $\mathrm{p}$ & $\beta(95 \% \mathrm{CI})$ & $\mathrm{p}$ \\
\hline PA & $-1.01(-3.14 ; 1.12)$ & 0.35 & & & & \\
\hline $\mathrm{BC}$ & & & $-74.30(-248.21 ; 96.62)$ & 0.40 & & \\
\hline $\mathrm{PA}+\mathrm{BC}$ & $-0.95(-3.09 ; 1.19)$ & 0.39 & $-68.87(-243.40 ; 105.66)$ & 0.44 & & \\
\hline $\mathrm{PA}+\mathrm{BC}+\mathrm{PAxBC}$ & $5.61(-1.65 ; 12.87)$ & 0.13 & $189.90(-133.77 ; 513.57)$ & 0.25 & $-4.73(-9.74 ; 0.28)$ & 0.07 \\
\hline \multicolumn{7}{|l|}{$\mathrm{FVC}(\mathrm{mL})$} \\
\hline PA & $0.10(-2.40 ; 2.60)$ & 0.94 & & & & \\
\hline $\mathrm{BC}$ & & & $19.59(-184.81 ; 223.99)$ & 0.85 & & \\
\hline $\mathrm{PA}+\mathrm{BC}$ & $0.08(-2.44 ; 2.61)$ & 0.95 & $19.11(-186.74 ; 224.95)$ & 0.86 & & \\
\hline $\mathrm{PA}+\mathrm{BC}+\mathrm{PAxBC}$ & $2.01(-6.67 ; 10.70)$ & 0.65 & $95.22(-292.22 ; 482.65)$ & 0.63 & $-1.39(-7.39 ; 4.60)$ & 0.65 \\
\hline \multicolumn{7}{|l|}{ FEV1/FVC (\%) } \\
\hline PA & $-0.03(-0.06 ; 0.004)$ & 0.09 & & & & \\
\hline $\mathrm{BC}$ & & & $-2.57(-5.10 ;-0.04)$ & 0.05 & & \\
\hline $\mathrm{PA}+\mathrm{BC}$ & $-0.02(-0.05 ; 0.01)$ & 0.23 & $-2.18(-4.73 ; 0.36)$ & 0.10 & & \\
\hline $\mathrm{PA}+\mathrm{BC}+\mathrm{PAxBC}$ & $0.09(-0.009 ; 0.19)$ & 0.08 & $2.21(-2.30 ; 6.72)$ & 0.34 & $-0.08(-0.15 ;-0.01)$ & 0.03 \\
\hline \multicolumn{7}{|l|}{$\mathrm{PEF}(\mathrm{mL} / \mathrm{s})$} \\
\hline PA & $-3.90(-9.66 ; 1.86)$ & 0.19 & & & & \\
\hline $\mathrm{BC}$ & & & $-208.10(-698.29 ; 282.08)$ & 0.41 & & \\
\hline $\mathrm{PA}+\mathrm{BC}$ & $-3.54(-9.41 ; 2.34)$ & 0.24 & $-144.61(-641.56 ; 352.34)$ & 0.57 & & \\
\hline $\mathrm{PA}+\mathrm{BC}+\mathrm{PAxBC}$ & $5.60(-13.61 ; 24.82)$ & 0.57 & $225.03(-663.26 ; 1131.32)$ & 0.62 & $-6.64(-19.90 ; 6.63)$ & 0.33 \\
\hline \multicolumn{7}{|l|}{$\mathrm{FEF}_{25-75}(\mathrm{~mL} / \mathrm{s})$} \\
\hline PA & $-2.37(-6.78 ; 2.04)$ & 0.30 & & & & \\
\hline $\mathrm{BC}$ & & & $-336.44(-718.72 ; 45.83)$ & 0.10 & & \\
\hline $\mathrm{PA}+\mathrm{BC}$ & $-1.60(-6.04 ; 2.85)$ & 0.49 & $-306.46(-695.13 ; 82.20)$ & 0.14 & & \\
\hline $\mathrm{PA}+\mathrm{BC}+\mathrm{PAxBC}$ & $14.54(-0.20 ; 29.27))$ & 0.06 & $344.86(-337.35 ; 1027.07)$ & 0.33 & $-11.70(-21.89 ;-1.51)$ & 0.03 \\
\hline
\end{tabular}

